\title{
A STUDY ON PATIENTS WITH PEPTIC ULCER PERFORATION WITH RESPECT TO AETIOLOGY AND FACTORS AFFECTING OUTCOME OF MANAGEMENT
}

\author{
Yeganathan Rajappan¹, Nagarajan Veerasamy², Mahalakshmi Ashokkumar ${ }^{3}$, Manimaran Thangavelu4, Anandan Kanthan ${ }^{5}$ \\ ${ }^{1}$ Associate Professor, Department of General Surgery, KAPV Govt. Medical College, Trichy. \\ 2 Post Graduate Student, Department of General Surgery, KAPV Govt. Medical College, Trichy. \\ ${ }^{3}$ Assistant Professor, Department of General Surgery, KAPV Govt. Medical College, Trichy. \\ ${ }^{4}$ Assistant Professor, Department of General Surgery, KAPV Govt. Medical College, Trichy. \\ ${ }^{5}$ Post Graduate Student, Department of General Surgery, KAPV Govt. Medical College, Trichy.
}

ABSTRACT
BACKGROUND
Perforation peritonitis is one of the commonest surgical emergency encountered by surgeons. The aim of the study is to provide
an overview of aetiological factors causing peptic ulcer perforation and the factors affecting the outcome of management.

\section{MATERIALS AND METHODS}

This study was conducted at Mahathma Gandhi Memorial Hospital, Trichirapalli, between December 2014 and August 2015. This study included 81 cases of Peptic ulcer perforation who are managed with laparotomy or peritoneal drainage, were studied retrospectively for the factors causing peptic ulcer perforation, site of perforation, surgical management, complications and outcome and factors influencing outcome of management. Data analysed done by using SPSS 17 software with appropriate statistical test.

\section{RESULTS}

The incidence of Peptic ulcer perforation at MGM Hospital has been worked out to be $<1 \%$ (0.74\%). Peptic ulcer perforation is commonly seen in $5^{\text {th }}$ decade of life; $65 \%$ of the cases in the age group of 25 to 55 years. The youngest patient was 15 years old and the oldest 70 years old. Male:Female ratio is 9:1. More commonly seen in people who are having blood group "0" constituting 49\% of the total. Past history of peptic ulcer was present in $73 \%$ of cases of perforation; $65.4 \%$ of the cases are addicted to chronic smoking and $66.7 \%$ of the cases are addicted to alcohol; $94 \%$ were taking mixed diet. Family history of peptic ulcer was present in $32 \%$ of the cases of duodenal ulcer perforation; $94 \%$ patients consume diet with plenty of chillies and spices. Out of $73 \%$ of cases with past history of duodenal ulcer, $80-85 \%$ of patients had taken medical treatment with antacids and $\mathrm{H} 2$ receptor blockers, proton pump inhibitors drugs irregularly. Diagnosis was made on clinical history and physical examination of abdomen and aided by plain X-ray abdomen in erect posture, which showed pneumo-peritoneum in $96.3 \%$ of cases of duodenal ulcer perforations. Obliteration of liver dullness was present in $80 \%$ to $86 \%$ of cases; $48.5 \%$ of the cases of perforated ulcer were in shock at the time of admission. The size of perforation is less than $5 \mathrm{~mm}$ in 13/81 cases. In only $9 / 81$ cases the size was more than $10 \mathrm{~mm}$, in $59 / 81$ of cases the size was 5 to $10 \mathrm{~mm}$. The site of perforation in 77 cases is on the anterior wall of first part of duodenum, 4 cases showed perforation at pylorus/Gastroduodenal junction. History of taking NSAID is an important aetiological factor in our study, persons having this history showed perforations of related larger size and higher incidence of death. In $96.3 \%$ of the cases, the operative procedure adopted is simple closure of the perforation with live omental patch. The longer the time interval between perforation of peptic ulcer and the operation, morbidity and mortality is high. Postoperative complications are seen more in cases with comorbid conditions like Diabetes Mellitus, Hypertension, Old age, Ischaemic heart disease. Average duration of stay in hospital after surgery in this study is 13.4 days. At MGM Hospital, Trichy in 81 cases of Peptic ulcer perforation studied from December 2014 to August 2015, the mortality rate is $13.5 \%$.

\section{CONCLUSION}

Smoking, Alcohol intake, Stress and NSAID intake, Blood group has significant association with peptic ulcer perforation. Out of 81 patients studied, 11 deaths occurred and the mortality rate is $13.5 \%$. Duration between onset of perforation and management is the most significant predictor for mortality. Associated comorbid conditions have significance in secondary outcomes, but does not show significant association to death.

\section{KEYWORDS}

Perforation, Peritonitis, Causes, Omentoplasty, Outcome.

HOW TO CITE THIS ARTICLE: Rajappan Y, Veerasamy N, Ashokkumar M, et al. A study on patients with peptic ulcer perforation with respect to aetiology and factors affecting outcome of management. J. Evolution Med. Dent. Sci. 2016;5(56):3857-3861, DOI: $10.14260 /$ jemds/2016/883

Financial or Other, Competing Interest: None.

Submission 31-05-2016, Peer Review 02-07-2016,

Acceptance 07-07-2016, Published 14-07-2016.

Corresponding Author:

Dr. Yeganathan Rajappan,

Associate Professor,

General Surgery,

KAPV Govt. Medical College, Trichy

E-mail: dryeganathan@gmail.com

DOI: $10.14260 /$ jemds $/ 2016 / 883$

\section{INTRODUCTION}

Peptic ulcer perforation is one among the common surgical emergency. $[1,2,3]$ faced in Southern India, mainly due to rice and spicy food intake. The peptic ulcer incidence is in raise in the era due to excess stress, alcohol intake, and varied and advanced investigative procedures easy access to health care facilities and better documentation. Now-a-days much news 
are getting put forth regarding treatment of peptic ulcer and its complication.

Aetiological factors in India differs from that in Western Countries.[3,4,5] Commonly seen in younger age group with mean age 38 years. ${ }^{[6,7,8]}$ Perforation peritonitis of all cause, most common in proximal GI tract.[9,10,11,12] Peptic ulcer perforation is the single largest cause for perforation. Perforation peritonitis has a slightly higher incidence in distal GI tract in West.[13-15] Infection is the second commonest cause followed by malignancy in India.[16] Western countries malignancy followed by infection are the causes.[17,18] Overall, mortality in Perforation peritonitis is $6-27 \% .{ }^{[19]}$ Mortality after surgery for PPU is between 6 and $10 \% .{ }^{[20]}$ There are four main factors which can increase this mortality rate even up to $100 \%$

These are age $>60$ years, delayed treatment $(>24 \mathrm{~h})$, shock at admission (Systolic BP $<100 \mathrm{mmHg}$ ) and concomitant diseases.[21,22] Also, gastric ulcers are associated with a two-tothreefold increased mortality risk.[21,22] Boey's score which is a score based on scoring factors as shock on admission, confounding medical illness and prolonged perforation has been found to be a useful tool in predicting outcome.[23]

\section{MATERIALS AND METHODS}

Study Place: Mahatma Gandhi Memorial Hospital and KAPV Govt. Medical College. Trichy.

Duration of Study: December 2014 to August 2015.

Study Design: Prospective Study.

Ethical Committee: Institutional Ethical Committee, KAPV Govt. Medical College. Approved on December 2014.

\section{Inclusion Criteria}

Age group between 13 and 70 years. All sex group Male:Female and Trans genders. Patients with past history of Peptic ulcer now with features of peritonitis. Patients with Radiological evidence of perforation.

\section{Exclusion Criteria}

Suspected or proven cases of preop or postop malignancy. Iatrogenic perforation-scopy/laparotomy. Traumatic perforations. Patients with peritonitis with no radiological evidence of perforation.

\section{Data Collection and Methods}

Patients admitted with features of peritonitis at Mahatma Gandhi Memorial Hospital, Trichy, were included in the study. History evaluation with structured questionnaire along with Biochemical, Radiological analysis done. Clinical features will be noted for all patients by using structured questionnaire and the patients will be followed up after management for outcome and complications. I have selected 81 cases of Peptic ulcer perforation admitted and managed in our Hospital during this period. Surgical management is done by Open Laparotomy and Perforation closure. Since Laparoscope facility is not available in Emergency theatre, all surgical management is done by open method.

\section{Analysis Plan}

Data analysed done by using SPSS 17 software with appropriate statistical test. Factors taken into account for predisposing cause are Sex, Age, History of Peptic ulcer, Family History, Blood Grouping, Smoking, Alcohol intake, NSAID intake, Stress, Steroid intake, Diabetes Mellitus, Hypertension, Bronchial Asthma, Ischaemic Heart Disease, Duration of Perforation. Factors taken into account in Outcome of
Management: Healed and discharged, Death, Paralytic Ileus, Wound infection, Wound dehiscence, Burst Abdomen, Sinus or fistula, Residual abscess, DVT, Pulmonary Basal Atelectasis.

\section{RESULT}

A general survey of Aetiology and Pathogenesis of Acute Peptic Ulcer Perforation has been made. A detailed study and analysis of the Peptic ulcer perforations during the period from December 2014 to August 2015, about 81 cases from MGM Hospital and KAPV Govt. Medical College has been made; 81 cases of Peptic ulcer perforations in the prospective study are hereby presented for the purpose of dissertation. The incidence of peptic ulcer perforation at MGM Hospital has been worked out $<1 \%(0.74 \%)$. Peptic ulcer perforation is commonly seen in $5^{\text {th }}$ decade of life, $65 \%$ of the cases in the age group of 25 to 55 years. The youngest patient of peptic ulcer perforation was 15 years old and the oldest patient was 70 years old. It is predominantly seen in male population. Male:Female ratio is 9:1. Peptic ulcer perforation is more commonly seen in people who are having blood group " $\mathrm{O}$ " constituting $49 \%$ of the total.

\begin{tabular}{|c|c|c|}
\hline Risk Factors & $\begin{array}{c}\text { Yes } \\
\text { (Percent) }\end{array}$ & $\begin{array}{c}\text { No } \\
\text { (Percent) }\end{array}$ \\
\hline Smoking & $53(65.4 \%)$ & $28(34.6 \%)$ \\
\hline Alcohol & $54(66.7 \%)$ & $27(33.3 \%)$ \\
\hline NSAID intake & $16(19.8 \%)$ & $65(80.2 \%)$ \\
\hline Steroid intake & $4(5 \%)$ & $77(95 \%)$ \\
\hline Stress & $12(14.8 \%)$ & $69(85.2 \%)$ \\
\hline
\end{tabular}

Past history of peptic ulcer was present in $73 \%$ of cases of duodenal ulcer perforation; $65.4 \%$ of the cases are addicted to chronic smoking and $66.7 \%$ of the cases are addicted to alcohol; $94 \%$ were taking mixed diet. Family history of peptic ulcer was present in $32 \%$ of the cases of duodenal ulcer perforation; $94 \%$ patients consume diet with plenty of chillies and spices. Out of $73 \%$ of cases with past history of peptic ulcer, $80-85 \%$ of patients had taken medical treatment with antacids and $\mathrm{H} 2$ receptor blockers, proton pump inhibitors drugs irregularly. In all the cases, the diagnosis was made on clinical history and physical examination of abdomen and aided by plain X-ray abdomen in erect posture which showed pneumoperitoneum in $96.3 \%$ of cases of duodenal ulcer perforations. Obliteration of liver dullness was present in $80 \%$ to $86 \%$ of our cases; $48.5 \%$ of the cases of perforated peptic ulcer were in shock at the time of admission.

\begin{tabular}{|c|c|c|}
\hline $\begin{array}{c}\text { Duration of Perforation } \\
\text { Pain }\end{array}$ & $\begin{array}{c}\text { No. of } \\
\text { Patients }\end{array}$ & Percentage \\
\hline 1 day & 9 & $11.1 \%$ \\
\hline 2 days & 46 & $56.8 \%$ \\
\hline 3 days & 16 & $19.8 \%$ \\
\hline 4 days & 9 & $11.1 \%$ \\
\hline 5 days & 1 & $1.2 \%$ \\
\hline \multicolumn{2}{|c|}{ Table 2: Duration of Onset of Perforation Pain } \\
\hline
\end{tabular}

Primary Outcome

\begin{tabular}{|c|c|c|}
\hline Death & Frequency & Percentage \\
\hline Yes & 11 & $13.5 \%$ \\
\hline No & 70 & $86.5 \%$ \\
\hline Total & $\mathbf{8 1}$ & $\mathbf{1 0 0 \%}$ \\
\hline \multicolumn{2}{|c|}{ Table 3: No. of Deaths in the Study Subjects } \\
\hline
\end{tabular}


Secondary Outcomes

\begin{tabular}{|c|c|c|}
\hline Outcomes & Yes & No \\
\hline Discharged with good healing & 70 & 11 \\
\hline Wound Infection & 30 & 51 \\
\hline Wound Dehiscence & 10 & 71 \\
\hline Paralytic ileus >3 days & 9 & 72 \\
\hline Sinus fistula & 1 & 80 \\
\hline Burst abdomen & 2 & 72 \\
\hline Residual abscess & 7 & 74 \\
\hline DVT & 1 & 80 \\
\hline Pulmonary Basal Atelectasis & 19 & 62 \\
\hline Table 4: Outcomes of the Study Subjects \\
\hline \multicolumn{2}{|l}{} \\
\hline \multicolumn{2}{|c}{}
\end{tabular}

\section{STATISTICAL RESULTS}

As the number of risk factors increases the mortality also increases and it is statistically significant with $P$-value 0.04 and Chi square for trend value 4.1. There is a significant association between number of days of onset of perforation pain with death showing Chi square for trend value 44.4, P-value 0.000, Degree of freedom 4. In this study, there is no statistically significant association ( $p>0.05)$ between diabetes mellitus, hypertension and death. Among the various risk factors, only NSAID intake showing significant association $(\mathrm{p}<0.006)$ between death and other risk factors are not statistically significant. Among the various risk factors, NSAID intake showing statistically significant association with secondary outcomes and for the smoking and alcohol intake there is no statistically significant association with secondary outcomes.

There is statistically significant association $(\mathrm{p}<0.05)$ between Diabetes mellitus and secondary outcomes. Chisquare value - 16.1, Degree of freedom - 3, P value - 0.001. In this study, there is statistically significant association $(\mathrm{p}<0.05)$ between hypertension and secondary outcomes with Chisquare value - 14.2, Degree of freedom - 3, P value - 0.003 .

\section{DISCUSSION}

Incidence of perforated peptic ulcer to total number of admissions in Surgical Department is less than 1\% (0.74\%). Incidence of Perforated peptic ulcer related to number of surgical emergency operated is $14.8 \%$. This incidence has been showing a trend of gradual decrease $2004-18.7 \%, 2008$ $-16.1 \%$. This might be due to increased awareness of peptic ulcer, better compliance of $\mathrm{H} 2$ antagonists, proton pump inhibitors and H. Pylori eradication management. Improved facilities in peripheral centers may also be a cause for decrease in incidence of peptic ulcer perforation cases along with increase in number of private hospitals in the vicinity.

Surgical emergencies done in KAPV Govt. Medical College Hospital between December 2014 and August 2015. Total cases 537 of which acute appendicitis 231, intestinal obstruction 96, perforated peptic ulcer 81 , blunt injury abdomen 37, others 102. Peptic ulcer perforation is the third commonest emergency surgery done in this institution. There is significant Male preponderance to Peptic ulcer perforation in our study. Out of 81 total cases, Male 73 and Female 8 cases. Male:Female ratio is 9:1. Ezra Steiger et al 2.5:1, Auram M. Cooperman et al - 10:1.[24] Youngest patient -15 years. Oldest patient - 70 years. Most common - Fifth Decade; 25 - 55 years - $65 \%$ of cases. A.K. Dev, S. Paul, N. Bhattacharjee, J. Roy Choudary Peak Incidence is 46 - 55 years.[25] Incidence of Peptic ulcer and Peptic ulcer perforation is common in Blood group " $\mathrm{O}$ " individuals; $49 \%$ of cases studied during the period
December 2014 to August 2015 in our hospital with Peptic ulcer perforation belong to " 0 " positive.

Plenty of other studies also showed 0 positive individuals more prone for Peptic ulcer disease $[25,26] ; 73 \%$ of patients had previous history of peptic ulcer (59/81); $27 \%$ of patients do not have history of peptic ulcer (22/81); Erza Steiger et al[24] $30-50 \%$ cases does not have past history; $65.4 \%$ of cases are habituated to smoking with duration $5-25$ years; $66.7 \%$ of cases habituated to alcohol intake; $94 \%$ of cases were taking mixed diet; $14.8 \%$ of cases giving history of stress. Rice is the staple diet in this region and all persons used to take spicy and consume chilies in their diet. Use of plenty of spicy and chilly ingredients in the diet along with smoking and alcohol intake predisposes to chronic peptic ulcer and precipitates perforation; $19.8 \%$ of persons had previous history of NSAID intake. Though NSAID intake is not a major predisposing factor in our region, as per many previous studies by S. H. Kulkarni et al and Dr. A. Y. Kashirsagar.[26] they remain main predisposing factor in Western countries, around 44\%. Family history present in $32 \%$ of cases in our institution in this study. Out of patients with history of peptic ulcer, $80-85 \%$ took treatment for ulcer with drugs like Proton pump inhibitors, H2 Antagonists, Antacids. Faulty patient's compliance seems to be an important factor in non-healing ulcer leading to perforation.

Diagnosis made by Detailed history, Clinical examination, Plain X-Ray Abdomen Erect/Lateral Decubitus position. Pneumoperitoneum seen in 78 out of 81 cases on first X-ray; 3 cases initially showed no air under Right dome of Diaphragm. After pushing 50-100 mL air through Ryles Tube air found visible under right dome of diaphragm. Operative findings: Peritoneal fluid, less than $500 \mathrm{~mL}$ in 5 cases, more than $500 \mathrm{~mL}$ in 76 cases. Size of perforation, less than $0.5 \mathrm{~cm}$ in 13 cases, 0.5 to $1 \mathrm{~cm}$ in 59 cases and more than $1 \mathrm{~cm}$ in 9 cases. Site, Duodenum in 77 cases and Gastric in 4 cases; 77 cases treated with Laparotomy, closure of Perforation with live omental patch, Peritoneal toileting given, bilateral or unilateral flanks drain kept; 4 cases initially treated with bilateral flanks drain due to poor general condition, of which one case improved from shock, hence laparotomy and closure of perforation after 2 days, other three cases died of irreversible shock.

\section{Post-Operative Complications}

\begin{tabular}{|c|c|c|}
\hline Complication & $\begin{array}{c}\text { This } \\
\text { Study }\end{array}$ & $\begin{array}{c}\text { Akdevroy } \\
\text { Choudry.[25] }\end{array}$ \\
\hline Wound Infection & 37 & 18 \\
\hline Prolonged Ileus & 11 & 7 \\
\hline $\begin{array}{c}\text { Wound } \\
\text { Dehiscence }\end{array}$ & 12 & 3 \\
\hline Pelvic Abscess & 9 & 5 \\
\hline Basal Atelectasis & 23 & 5 \\
\hline \multicolumn{2}{|r|}{ Table 5: Complications of Management } \\
\end{tabular}

Most cases had superficial wound infection, which healed spontaneously after draining by removal of few stitches; 12 of the cases with infection progressed to wound dehiscence and of which two cases went for burst abdomen, which was managed with tension suturing, other cases with wound dehiscence secondary suturing was done. All the cases healed well with prolonged hospital stay. Time elapsed between onset of perforation and treatment is the single most important factor in the prognosis. Time elapsed is less than 24 hours in 9 
cases, 24 to 48 hours in 46 cases, more than 48 hours in 26 cases. Average hospital stay in alive cases is 13.7 days. Prolonged hospital stay in cases with wound dehiscence and burst abdomen, which extended to a maximum of 28 days.

\section{Mortality}

\begin{tabular}{|c|c|c|c|}
\hline & Male & Female & Overall \\
\hline This Study & $13.7 \%$ & $12.5 \%$ & $13.5 \%$ \\
\hline AK Dev, Roy Choudry.[25] & & & $5 \%$ \\
\hline $\begin{array}{c}\text { SK. Kulkarni, AY. } \\
\text { Kshirsagar.[26] }\end{array}$ & & & $7.5 \%$ \\
\hline \multicolumn{3}{|c|}{ Table 6: Mortality Rate } \\
\hline
\end{tabular}

Mortality in our study is $13.5 \%$, which is slightly higher than other Indian studies. This might be due to delay in admission after onset of perforation pain and more number of patients admitted with shock at presentation.

\section{CONCLUSION}

Smoking, Alcohol intake, Stress and NSAID intake, Blood group has significant association with peptic ulcer perforation. Duration between onset of perforation and management is the single most significant predictor for mortality. Associated comorbid conditions have significance in secondary outcomes, but do not show significant association for mortality.

\section{ACKNOWLEDGEMENTS}

I thank the DEAN of K.A.P.V. Govt. Medical College, Trichy; Prof. Dr. MK. Muralitharan M.S., MCh., for permitting me to conduct this study in the Department of General Surgery of K.A.P.V. Government Medical College, Trichy. I thank Prof. A. Thulasi M.S., D.G.O., Head of Department of General Surgery and my Unit Chiefs and Associate Professor Dr. R. Yeganathan M.S., D. A, and Dr. P. Shanthini M.S., D.G.O., for helping and guiding during this study. I am greatly thankful to my Assistant Professors Dr. S. Srihari, M.S., Dr. W. Edwina Vasantha M.S., D.G.O., Dr. Mahalakshmi Ashokkumar M.S., D.G.O., Dr. Manimaran M.S., who have put in countless hours in guiding me in many aspects of this study and also in honing my surgical skills. I also thank Assistant Professor Dr. Venkatesan M.D. (SPM) who guided me in analysing the statistical aspects of the study. My gratitude to the Professors and Assistant Professors of all other Units. I thank my fellow Post Graduates who helped me in conducting the study. Last but not the least, I am thankful to my patients without whom this study could not have been completed.

\section{REFERENCES}

1. Ramakrishnan K, Salinas RC. Peptic ulcer disease. The American Family Physician 2007;76(7):1005-12.

2. Ersumo T, Kotisso B. Perforated peptic ulcer in tikur anbessa hospital: a review of 74 cases. Ethiopian Medical Journal 2005;43(1):9-13.

3. Sharma L, Gupta S, Soin AS, et al. Generalized peritonitis in India-the tropical spectrum. Japanese Journal of Surgery 1991;21(3):272-7.

4. Bose SM, Kumar A, Chaudhary A, et al. Factors affecting mortality in small intestinal perforation. Indian Journal of Gastroenterology 1986;5(4):261-3.

5. Nadkarni KM, Shetty SD, Kagzi RS, et al. Small-bowel perforations. A study of 32 cases. Archives of Surgery 1981;116(1):53-7.
6. Svanes C, Salvesen H, Espehaug B, et al. A multifactorial analysis of factors related to lethality after treatment of perforated gastroduodenal ulcer. 1935-1985. Annals of Surgery 1989;209(4):418-23.

7. Watkins RM, Dennison AR, Collin J. What has happened to perforated peptic ulcer? British Journal of Surgery 1984;71(10):774-6.

8. Uccheddu A, Floris G, Altana ML, et al. Surgery for perforated peptic ulcer in the elderly. Evaluation of factors influencing prognosis. Hepato-Gastroenterology 2003;50(54)1956-8.

9. Agarwal N, Saha S, Srivastava A, et al. Peritonitis: 10 years' experience in a single surgical unit. Tropical Gastroenterology 2007;28(3):117-20.

10. Malangoni MA, Inui T. Peritonitis-the western experience. World Journal of Emergency Surgery 2006;1(1):25.

11. Bohnen J, Boulanger M, Meakins JL, et al. Prognosis in generalized peritonitis. Relation to cause and risk factors. Archives of Surgery 1983;118(3):285-90.

12. Dean ACB, Clark CG, Sinclair-Gieben AH. The late prognosis of perforated duodenal ulcer. Gut 1962;3(1):60-64.

13. Gupta S, Kaushik R, Sharma R, et al. The management of large perforations of duodenal ulcers. BMC Surgery 2005;5:15.

14. Mandava N, Kumar S, Pizzi WF, et al. Perforated colorectal carcinomas. The American Journal of Surgery 1996;172(3):236-8.

15. Di Venere B, Testini $M$, Miniello $S$, et al. Rectal perforations. Personal experience and literature review. Minerva Chirurgica 2002;57(3):357-62.

16. Khanna AK, Misra MK. Typhoid perforation of the gut. Postgraduate Medical Journal 1984;60(706):523-5.

17. Breitenstein S, Kraus A, Hahnloser D, et al. Emergency left colon resection for acute perforation: primary anastomosis or Hartmann's procedure? A case-matched control study. World Journal of Surgery 2007;31(11):2117-24.

18. Roviello F, Rossi S, Marrelli D, et al. Perforated gastric carcinoma: a report of 10 cases and review of the literature. World J Surg Oncol 2006;4:19.

19. Oheneh-Yeboah M. Postoperative complications after surgery for typhoid ileal perforation in adults in Kumasi. West African Journal of Medicine 2007;26(1):32-6.

20. Imhof M, Epstein S, Ohmann C, et al. Duration of survival after peptic ulcer perforation. World J Surg 2008;32(3):408-12.

21. Zittel TT, Jehle EC, Becker HD. Surgical management of peptic ulcer disease today-indication, technique and outcome. Langenbecks Arch Surg 2000;385(2):84-96.

22. Sarosi GA, Jaiswal KR, Nwariaku FE, et al. Surgical therapy of peptic ulcers in the 21st century: more common than you think. Am J Surg 2005;190(5):775-9.

23. Bucher P, Oulhaci W, Morel P, et al. Results of conservative treatment for perforated gastroduodenal ulcers in patients not eligible for surgical repair. Swiss Med Wkly 2007;137(23-24):337-40.

24. Steiger E, Cooper AM. Considerations in the management of perforated peptic ulcers. Surgical Clinics of North America 1976;56(6). 
25. Dev AK, Paul SN, Roychowdary J, et al. Perforated duodenal ulcer. Indian J Surgery 1994;56(5):222-7.
26. Kulkarni SH, Kshirsagar AY. Factors that predict mortality and morbidity in patients with simple closure of perforated duodenal ulcer. Journ of Indian Medical Association 1998;96:24. 